OPEN ACCESS

\title{
Technopolis and Regional Development : A Review of Development Experience in Hsinchu, Taiwan
}

\author{
Tai-Shan Hu' and Chien-Yuan Lin*2 \\ Department of Architecture and Urban Planning, Chung-Hua University, Graduate Institute of Building and Planning, National Taiwan University, \\ Hsinchu, Taiwan
}

\begin{abstract}
The Hsin-Chu Science-Based Industrial Park (HSIP), established in 1980, has made significant contribution to the development of Hsinchu technopolis. In the past three decades, not only the population structure and industrial patterns have changed significantly, but also a special knowledge-based industrial network has been developed. The 30 years experience of HSIP development provides an excellent opportunity for planners to review the long term impacts of science park development. This paper will review the evolution Hsinchu technopolis in areas of socioeconomic transformation and knowledge interactions between technology community and industrial clustering. In addition to the interpretation of its development by prevailing theories, critical factors influencing the future development of HSIP technopolis will also be discussed in this paper.
\end{abstract}

Keyword: HSIP, Technopolis, High-tech Cluster, Technological Community, Innovation and Production Network

\section{INTRODUCTION}

Asian countries frequently use strategic investments, typically by central government, to develop technology-based clusters or cities to serve as growth engines for regional development. Science parks are generally perceived as local or regional growth centers (Bass 1998; Oh 1995). Through public investments in science parks, both industrial advancement and local development of related industries and businesses are promoted.

In order to promote national economy and balanced regional population growth, the central government of

*Correspondence to : Prof. Chien-Yuan Lin

Professor, Graduate Institute of Building and Planning, National Taiwan University, Taipei Taiwan.

E-mail : cylin@ntu.edu.tw

World Technopolis Review

Copyright $(\odot$ World Technopolis Association

CC This is an open-access article distributed under the terms of the Creative Common Attribution Non-Commercial License(http://creativecommons.org/licenses/by-nc/3.0) which permits unrestricted noncommercial use, distribution, and reproduction in any medium, provided the original work is properly cited
Taiwan had developed a series of Major Development Initiative projects since 1970s. One of them was the establishment of Hsinchu Science-Based Industrial Park (HSIP) in 1980 aiming at developing Hsinchu into a high-tech research base with high quality, strong growth and high efficiency. In a comprehensive assessment of Hsinchu technopolis, Lin (1997) concluded that HSIP had significantly promoted the national and regional economy, yet, the spontaneous spatial development pattern of Hsinchu technopolis was not exactly as planned in the Comprehensive Development Plan of Hsinchu Science City. Lin (1997) also concluded that it would be more reasonable to evaluate the long-term impacts after at least 25 years.

In 2011, the total HSIP sales reached $\$ 34.487$ billion and it represented about $10 \%$ of total manufacturing output in Taiwan. It is evident that HSIP has closely integrated with regional industries and local development. The concentration of high-tech and innovative firms transformed into a regional development force, which led to the emergence of Hsinchu technopolis over the past thirty years. <Fig. 1> shows the geography of Hsinchu technopolis, including 


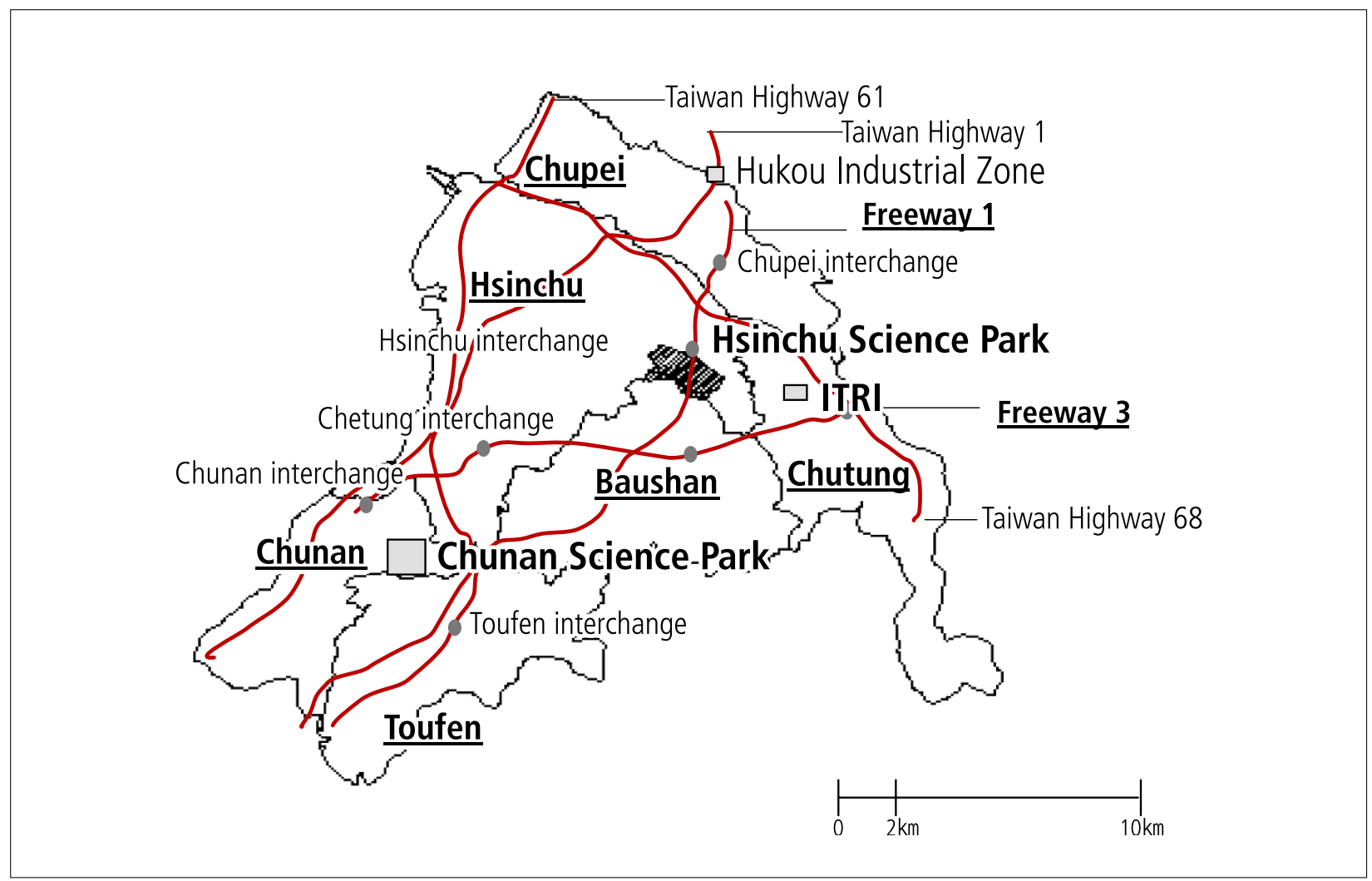

Fig. 1. Hsinchu Technopolis: Location and Major Infrastructure and Urban Characteristics

HSIP, Hsinchu city and Hsinchu county.

Between 1982 and 2011, its population increased by over 150,000 persons. This population growth exceeded the average in Northern Taiwan. The average rate of social increase in Hsinchu is 1.21\% from 1982 to 2011. These statistics exhibit a strong trend of inwards migration in Hsinchu. According to the 2011 statistics of the Hsinchu ScienceBased Industrial Park Bureau (HSIPB), the development of HSIP has contributed significantly to local employment. Notably, thirty percent of Hsinchu's manufacturing workforce was employed in HSIP in 2011. Moreover, despite rising unemployment in Taiwan during the past decade, Hsinchu maintains a low unemployment rate and high labor force participation rate compared to the rest of Taiwan.

With the rapid development of HSIP, the total number of employees increased to over 137,256 persons in 2011, while the total number of companies increased to approximately 477. Most of these employees are highly educated and highly paid. HSIP transformed the local industrial structure, activated and diversified consumer behavior, represented a new urban development pattern, and altered population composition. Restated, the age structure in Hsinchu has altered significantly during the past three decades. Notably, growth rates in the 30 to 40 and 40 to 49 age groups, are $87.41 \%$ and $74.21 \%$, respectively. This growth trend clearly reflects the strong demand of HSIP for employees aged 30 to 50 , demonstrating that HSIP has not only influenced the local economy, but also the local population structure.

The long-term effects of HSIP development on a locality demonstrate a development model different from that of traditional industries, plus the continuous input of new knowledge, helping sustained market competitiveness. The success of science parks is related to local educational institutions, infrastructure, and R\&D funding(Westhead and Batstone 1998). Direct costs can be minimized through collaboration between science parks and R\&D institutions. Furthermore, companies located in science parks can benefit from developing and sharing new information and applying it in their businesses. The convenience provided by science parks encourages the agglomeration of the technology 


\section{Special Contribution}

industry. Collaboration among science park companies, research institutions and universities is essential to science parks. This collaboration, along with the concentration of companies in the vicinity, leads to the creation of an innovative network. The characteristics of innovation, on which the knowledge economy depends (Audretsch 1998; Feldman et al. 1994; Saxenian 1994), emphasize spatial proximity, localized learning network, and face-to-face interactions. These characteristics promote the agglomeration of high-tech industries around HSIP, creating a localized innovation environment. Additionally, the Industrial Technology Research Institute (ITRI) began to extend and establish laboratories and innovative incubators in HSIP since 1995. Over 60\% of the incubated companies chose to locate in the Hsinchu area (including both Hsinchu City and Hsinchu County) or the nearby areas (i.e. in the northeast of Hsinchu area), expanding the production space around HSIP to include traditional industrial production space, demonstrating how high-tech industry agglomeration caused a reform of production space.

The agglomeration of high-tech industries, the local production network created by the technological infrastructure in the vicinity, and the related knowledge and informal information flow generated by local universities, form a continuously strengthening agglomerative economy, which has become the force increasing the production capacity of the Hsinchu technopolis. The success of HSIP and the formation of Hsinchu technopolis demonstrate that Science / Technology Park (STP) is an effective tool for integrating industry and regional development. Through the review of previous related studies (Hu et al. 2005a; 2005b; 2006; Chang et al. 2010), this paper intends to investigate the long term influences and the development process of Hsinchu technopolis in terms of the formation and evolution of a technology-based metropolitan area and its innovative environment. In addition, the critical factors influencing the future development of Hsinchu technopolis will be discussed.

\section{SOCIOECONOMIC EVOLUTION OF HSINCHU TECHNOPOLIS}

During the past three decades, HSIP has grown significantly and created a large number of jobs for technical labor force with high education degree and payment. This indus- trial production capability has also become a driving force for attracting related industries and labors to HSIP and its surrounding area. The subsequent entry and establishment of related business service industries have further transformed the overall industrial structure of Hsinchu, and simultaneously restructured its urban space and led to the formation of Hsinchu technopolis. Four development stages were defined for HSIP, namely the initial stage from 1984 to 1988, the stable development stage from 1989 to 1993, and the rapid growth stage from 1994 to 1998, and rapid globalization stage from 1999 up to now.

\subsection{Changes in Population and Communities around HSIP}

Cities in Northern Taiwan have maintained steady population growth with growth rates ranging from 0.79 to 2.89 in 1980-2011. Comparing population growth rates of major cities in Northern Taiwan, the Hsinchu districts (1.44-6.44) exhibited more significant growth from 1986 to 2011 than the average of the entire Northern Region. These high growth rates correspond with the structural changes recently experienced by Taiwanese industry, namely, the prosperous development of the high-tech industry, the successive establishment of high-tech companies in HSIP and the consequent employment wave in HSIP. Both steady industrial development and population growth demonstrate the long term influences of HSIP on the technopolis development.

HSIP has attracted migrants from all over Taiwan, as evidenced in the employment statistics of the HSIPB < Table $1>$. The number of new residents in Hsinchu area also increased with the rapid increase of HSIP employees. Meanwhile, the number of HSIP employees originally from the Hsinchu area decreased. Because of the aggressive expansion of HSIP companies, a significant number of current HSIP employees migrated to the Hsinchu area from other parts of Taiwan. Meanwhile, employees chose to commute to HSIP also increased by approximately $14 \%$.

From the analyses of population growth and change, it can be concluded that the development of the area around HSIP grew or declined in different ways during different stages. During the initial stage of HSIP, migrants attracted by HSIP resided primarily in the fringe of the Hsinchu urban core. After 1986, the inner suburbs became saturated, and development began to slow down in 1993. Moreover, the development of this neighborhood remained slow from 1979 through 1986. However, residential development adja- 


\begin{tabular}{l|c|cc|cc|c}
\hline & 1990 & \multicolumn{2}{|c|}{1997} & 2000 & 2011 \\
\cline { 2 - 7 } & $\begin{array}{c}\text { Number of employ- } \\
\text { ees who originally } \\
\text { came from: } \\
(\%)\end{array}$ & $\begin{array}{c}\text { Number of employ- } \\
\text { ees who originally } \\
\text { came from: } \\
(\%)\end{array}$ & $\begin{array}{c}\text { Number of employ- } \\
\text { ees who reside in: }\end{array}$ & $\begin{array}{c}\text { Number of employ- } \\
\text { ees who originally } \\
\text { came from: } \\
(\%)\end{array}$ & $\begin{array}{c}\text { Number of employ- } \\
\text { ees who reside in: }\end{array}$ & $\begin{array}{c}\text { Number of employ- } \\
\text { ees who reside in: }\end{array}$ \\
\hline Hsinchu City & 2,690 & 18,211 & 24,442 & 24,444 & 35,395 & $(\%)$ \\
Hsinchu & $(37.90)$ & $(32.62)$ & $(43.79)$ & $(24.29)$ & $(35.17)$ & 46,150 \\
County & 2,107 & 15,136 & 15,673 & 20,999 & 22,687 & $(33.62)$ \\
Other Cities and & $(29.68)$ & $(27.12)$ & $(28.08)$ & $(20.86)$ & $(22.54)$ & 39,821 \\
Counties & 2,300 & 22,470 & 15,702 & 55,206 & 42,567 & $(29.01)$ \\
Total & $(32.42)$ & $(40.26)$ & $(28.13)$ & $(54.85)$ & $(42.29)$ & 51,285 \\
\hline
\end{tabular}

Source: HSIPB, 2012

cent to HSIP began to follow up after 1986, and residential mixed-use development, combining residential and commercial uses, became a new trend from 1993.

Excellent research and development (R\&D) institutions, a comprehensive business R\&D structure, high quality of life and strong business networks are crucial in helping a region become a technopolis, in turn creating wealth and high value work opportunities (Oh and Cha 2001). HSIP possesses all these characteristics. In Taiwan, development policy defines a technopolis and science park as differing in that the former provides land for high-tech industries and creates an environment that fosters research, while the latter encourages high-tech industries to locate in undeveloped areas. Masser (1991) further observed that a technopolis is larger and generally possesses essential infrastructure, while science parks are more production-oriented and are generally tied to national or regional development goals. Although the Hsinchu Technopolis Development Plan was created for the Hsinchu area in 1993, with the aim of transforming the Hsinchu area into a high-tech region, it failed owing to a lack of motivation on the part of the local government, difficulties in making zoning changes, weak regulatory support for the development of private infrastructure, and weak implementation team organization (Lin 1997). From the perspective of residential locations for science and technology communities, the spatial expansion of the Hsinchu area has strong tacit congregation power over knowledge interactive learning and local culture identity and thus establishes geographic boundaries for residential areas (Hu et al. 2010).

\subsection{Changes in Industrial Production Space}

Looking at the process of industrial growth in HSIP, the first professional semiconductor manufacturer in Taiwan emerged with the creation of Taiwan Semiconductor Manufacturing Company in 1987. This development marked the beginning of formal cooperation between semiconductor design companies and manufacturers in Taiwan. After 1991, a mutual dependency developed between innovative technology from Silicon Valley and the mass production facilities in Hsinchu. However, global competition pressure led both design companies and related service companies to locate in HSIP to facilitate the quick resolution of any issues arising during the manufacturing problems. The extensive production capacity at HSIP further attracted more companies to locate there. By 2001, HSIP had reached saturation over 300 companies in the park. Consequently, some companies that who could not be accommodated in HSIP ended up to locate in outside areas around HSIP. To choose a factory site, companies generally prefer HSIP to other locations because of its rent and tax incentives, plus the advantage of innovative interactions with other companies. The second most popular choice of location is the industrial park around HSIP.

Among these areas, the Hsinchu Hu-Ko Industrial District, linked to HSIP by the National Freeway 1, initially focused on traditional industries, such as ceramics, glass, beverage, and chemical manufacturing. In 1991, the chemical and plastics manufacturing industry accounted for $23 \%$ of the total 337 companies involved in this district, metal and mechanical 


\section{Special Contribution}

industries accounted for 20\%, and electronics accounted for just 15\%. By 1996, the chemical, plastic, metal and mechanical industries continued to account for most (41\%) of the 339 companies located in this district, but the share of the electronics industry had increased to $21 \%$. Meanwhile, by 1999, electronics companies represented 30\% of the 352 companies. Among these electronics companies, semiconductor companies accounted for $40 \%$.

It is also interesting to witness the land use conversion of traditional industrial parks where many factory buildings abandoned from traditional industries became adaptivereuse spaces for high-tech industries. They were preferred by high-tech companies because of its excellent accessibility from HSIP and affordable land prices. A major driver of such development, besides the involvement of HSIP, came from the provision of key technology infrastructure nearby in the form of ITRI. One of the typical case is the development of Tai-Yen Science Park privately developed. Additionally, many spin-off innovative companies chose to locate in the ChuTung and Hsinchu Industrial Districts on the east and west sides of HSIP because of their proximity to universities, research institutions and HSIP itself. These companies then tried to move into HSIP, or else sought alternative locations in the surrounding area. This phenomenon led to the construction of office and factory mixed-use buildings in the vicinity of HSIP. These buildings provided space not only for new innovative companies, but also for producer service industries to serve HSIP.

\subsection{Emerging of Innovation Environment in and around Hsinchu City}

The cost of communications has reduced significantly due to the progress of telecommunication technology. However, because of the ambiguity and uncertainty of new knowledge, high-tech companies still depend on the face-to-face interactions facilitated by spatial clustering, and thus location remains important. That is, Knowledge-based economic activities or innovative activities usually cluster in areas with rich base of scientific knowledge related to specific industries (Baptista 1996), which is why only companies located in a handful areas of the world are capable to utilize new knowledge in production and commercialization. Furthermore, the more R\&D is inputted into a clustered space, the faster new technologies and products can be released, the greater the profits from new technologies and products will be, and the more innovative outcomes will be stimulated. The total corporate spending on $R \& D$ in the Hsinchu District in 1990 reveals that only 56\% came from companies located in HSIP. However, by 1998, this figure has increased to 84\%. From 1990 through 1999, the R\&D capital input of companies in HSIP increased 10 fold, exceeding not only that of companies in the wider Hsinchu District, but also exceeding the national average. This phenomenon was further evidenced in the dominance of information tech-

Table 2. Technological Transfer of Electrical and Electronic Machinery in Hsinchu District and Northern Taiwan Region by Number of Companies and Value

\begin{tabular}{|c|c|c|c|c|c|c|}
\hline & \multicolumn{2}{|c|}{ Hsinchu District } & \multicolumn{2}{|c|}{ Northern Taiwan } & \multicolumn{2}{|c|}{ The ratio of Hsinchu District / Northern Taiwan } \\
\hline & Number of Companies & US \$ (thousand) & Number of Companies & US \$ (thousand) & By Number of Companies & By US $\$$ \\
\hline 2010 & 76 & 5,610 & 196 & 16,140 & 0.388 & 0.348 \\
\hline 2008 & 45 & 6,860 & 141 & 24,100 & 0.319 & 0.285 \\
\hline 2006 & 68 & 6,780 & 177 & 17,880 & 0.384 & 0.379 \\
\hline 2004 & 96 & 4,620 & 318 & 15,240 & 0.302 & 0.303 \\
\hline 2002 & 67 & 3,760 & 214 & 11,090 & 0.313 & 0.339 \\
\hline 2000 & 71 & 4,500 & 224 & 9,720 & 0.317 & 0.464 \\
\hline 1998 & 79 & 3,280 & 231 & 6,380 & 0.342 & 0.514 \\
\hline 1996 & 52 & 4,650 & 165 & 6,040 & 0.315 & 0.770 \\
\hline 1994 & 49 & 1,050 & 198 & 4,660 & 0.247 & 0.227 \\
\hline
\end{tabular}

Source: ITRI 
nology hardware of publicly traded semiconductor companies in the US software patents registered by Taiwanese companies, revealed in the statistics collected by the Industrial Development Bureau, Taiwan Ministry of Economic Affairs. Among these companies and institutions, 70\% were located in Hsinchu District.

R\&D capital input level further stimulates competition among companies or agents, as demonstrated clearly by the number of patents generated by companies in HSIP and ITRI. Both ITRI and United Microelectronics Corp. play key roles in the local electronic industry as technology transfer agents. The technology transfers originated by the Specialized Science Technology Projects of ITRI distributed mainly in the information electronics industries in Hsinchu $<$ Table $2>$. The clustering of related or similar industries in a particular geographic location benefits the accelerated release of new discoveries or the acquisition of market share information. Consequently, both speed and intensity of innovation activities increase. The cluster of R\&D capital input not only increases innovation energy, but also boosts profits from industrial activities that rely on new knowledge.

\section{INVISIBLE ASSET: INTERACTIONS BETWEEN THE TECHNOLOGICAL COMMU- NITY AND INDUSTRIAL CLUSTERING}

After three decades of development, HSIP currently contains about 477 companies in 2011, with a total annual production of $\$ 34.487$ billion <Table $3>$. Since the 477 companies in the HSIP are very attractive to technical workers, the quality of the labor forces has improved considerably. As summarized earlier in this paper, the vicinity of HSIP also experienced major changes parallel to HSIP's rapid growth. All these developments contributed to the formation of Hsinchu technopolis.

Through a sampling survey, the innovative activity and interactions within production chains in the Hsinchu area are investigated in terms of knowledge agent spin-offs and high-tech talent mobility. ${ }^{1}$

\subsection{Innovation and Production Chains in Industrial Clusters}

The influx of research organizations, academic institutions and R\&D activities in the Hsinchu area has contributed to the marked regional clustering of the high-tech industry. As Baptista (1996) noted, knowledge economy activities or innovative activities generally are concentrated in areas that are rich in scientific knowledge relevant to the specific industry. Restated, given the proximity, knowledge stimulates interaction, which in turn fosters more effective knowledge production and transfer. This process leads new knowledge-based economic activities to become concentrated in

Table 3. Total Number of Companies in Operation and Combined Sales in HSIP

\begin{tabular}{|c|c|c|c|c|c|c|c|c|c|c|c|c|}
\hline \multirow{3}{*}{$\begin{array}{l}\text { Number of firms } \\
\text { Sales } \\
\text { (Million U.S.\$) }\end{array}$} & 1981 & 82 & 83 & 84 & 85 & 86 & 87 & 88 & 89 & 90 & 91 & 92 \\
\hline & 17 & 26 & 37 & 44 & 50 & 59 & 77 & 94 & 105 & 121 & 137 & 140 \\
\hline & -- & -- & 106 & 337 & 372 & 602 & 974 & 1,736 & 2,125 & 2,442 & 2,903 & 3,468 \\
\hline \multirow{3}{*}{$\begin{array}{l}\text { Number of firms } \\
\text { Sales } \\
\text { (Million U.S.\$) }\end{array}$} & 1993 & 94 & 95 & 96 & 97 & 98 & 99 & 00 & 01 & 02 & 03 & 04 \\
\hline & 150 & 165 & 180 & 203 & 245 & 272 & 292 & 289 & 312 & 334 & 369 & 384 \\
\hline & 4,905 & 6,706 & 10,940 & 11,565 & 13,915 & 13,693 & 20,387 & 28,146 & 20,331 & 23,349 & 26,324 & 36,197 \\
\hline \multirow{3}{*}{$\begin{array}{l}\text { Number of firms } \\
\text { Sales } \\
\text { (Million U.S.\$) }\end{array}$} & 2005 & 06 & 07 & 08 & 09 & 10 & 11 & & & & & \\
\hline & 382 & 392 & 416 & 430 & 440 & 449 & 477 & & & & & \\
\hline & 32,933 & 37,381 & 38,212 & 33,599 & 29,450 & 39,564 & 34,487 & & & & & \\
\hline
\end{tabular}

Source: HSIPB, 2012

\footnotetext{
${ }^{1}$ The survey questions mainly dealt with three areas - frequency of interaction among high-tech personnel and mobility of high-tech talent. The firms were in the integrated circuit, computer and peripheral, telecommunications, and opto-electronics sectors. Some 600 questionnaires were distributed and 243 usable responses were returned.
} 


\section{Special Contribution}

particular geographical regions (Audretsch 1998).

During the decade of rapid development in the HSIP (1990-1999), approximately $25 \%$ of the 171 new firms established at the HSIP were spin-offs established by ITRI. These spin-offs constituted the original local technological infrastructure. Among these spin-offs, ten firms were successfully developed by ITRI's Incubation Center, which was established in 1996. Moreover, during 1996-2003, approximately $80 \%$ of the firms developed by the Incubation Center chose to locate in the Hsinchu area (including 40\% in the HSIP and $38 \%$ elsewhere), establishing a local innovation chain that begins with research and development, is followed by incubation and results in the spinning-off of a new company.

Second, during the government-sponsored ITDP from 1994 to 2000, almost 90\% of partner firms in the IT and electronics industries were in northern Taiwan. Within the Hsinchu area, most technology transfers, in terms of both frequency and value, occurred in the IT and electronics industries. Over $80 \%$ of all technological transfers in all industries ${ }^{2}$ in the Hsinchu area were in the IT and electronics industries.

In relation to Taiwan as a whole, and even to the northern region in which IT/electronics are concentrated, firms in the
Hsinchu area are highly specialized. However, this situation brings up the question - does this specialization and centralization create a realistic and close-knit industrial network? Consequently, besides addressing transfers of technology under government-sponsored ITDP and production and cooperation among firms, this work also discusses the area production chain based on the collected company prospectuses, with reference to firm investment in production and the spatial distribution of production.

Technological cooperation among firms in various industries involves five main types - contracted technical cooperation, involving licensing or transfer of technology, which together comprise most cooperation. These types are followed by achievement transfer, technological cooperation and patent licensing. $<$ Table $4>$ reveals that most cooperating R\&D partners in the integrated circuit, computer and peripherals, telecommunications and opto-electronics industries, already mentioned, as well as in other industries, are research or academic institutions in the Hsinchu area, with ITRI at the center and National Chiao-Tung University and National Tsing-Hua University at the periphery. This arrangement is the same as for ITDP-related technology transfers, mentioned earlier.

Table 4. Partners and Geographical Distribution of R\&D Cooperation within Industries

$(\%)$

\begin{tabular}{lcc|cccc}
\hline & \multicolumn{2}{c}{ Partner } & \multicolumn{3}{c}{ Geographical istribution } \\
\cline { 2 - 7 } & R\&D Institutes & Firm & Hsinchu Area & Northern Taiwan & Other & Overseas \\
\hline Integrated Circuits & 27.6 & 72.4 & 38.8 & 22.9 & 3.8 & 34.5 \\
Computer and Peripherals & 88.9 & 11.1 & 88.9 & 0.0 & 0.0 & 11.1 \\
Communications & 80.0 & 20.0 & 60.0 & 26.7 & 0.0 & 13.3 \\
Optical Electronics & 73.9 & 26.1 & 65.1 & 8.6 & 4.6 & 21.7
\end{tabular}

Source: Prospectus of Listed Companies, Taiwan Stock Exchange Corporation

Moreover, most contracts governing technological cooperation involve technology transfer. The second largest number involves technology licensing. In contrast, most technological cooperation contracts between local and other firms are in the integrated circuit industry (over 70\%). Furthermore, most contracts for technological cooperation involve foreign firms, followed by firms from northern Taiwan. Domestic research institutions represent most firm contracted technological cooperation partners, with nearby institutions comprising the largest fraction. Furthermore, technological relationships among local firms are weaker than those with domestic research institutions, even among firms in the same area.

Additionally, the production and trade network of firms

\footnotetext{
${ }^{2}$ All types of industry include agriculture, forestry, fishery, animal husbandry and mining, manufacturing, water, electricity, fuel and natural gas, metal and mechanics, IT and electronics, chemical engineering, household trades, service and others. (Source: ITRI's Technology Service Center)
} 
within the HSIP $<$ Fig. $2>$ and $<$ Fig. $3>$ show that interaction, including critical investment and product sales, within firms in northern Taiwan is quite extensive (exceeding 70\%). Meanwhile, the production and trade network involving firms outside the HSIP but within the Hsinchu area is relatively weak. Accordingly, combining the previously men-

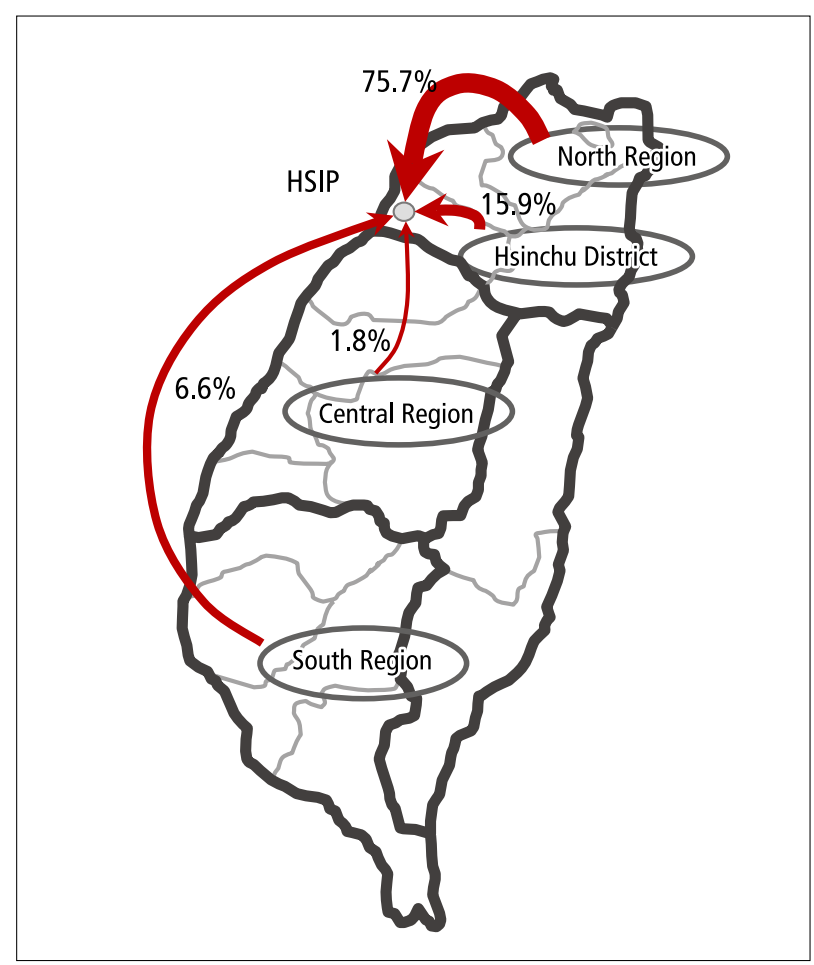

Fig. 2. Input Network in Hsinchu Technopolis

However, the results also indicate that the Hsinchu area is characterized by spatial proximity or interaction with overseas firms in innovative technological interaction. Furthermore, new firms tend to cluster in the Hsinchu area. On maturity, around $40 \%$ of these corporations are likely to expand further in northern Taiwan following three to five years. Some firms might even, after five to eight years, go beyond their current cluster to form links with other clusters, especially clusters in Mainland China.

Recently, almost 30\% of firms in the HSIP have already opened offices in or shifted production to Mainland China. tioned ITDP technology transfers, technological cooperation contract relations and production trade networks yield the initial results of this work, indicating that northern Taiwan is a complete and comprehensive local industrial cluster ${ }^{3}$ characterized by clustered trade interaction and weak innovating interactions.

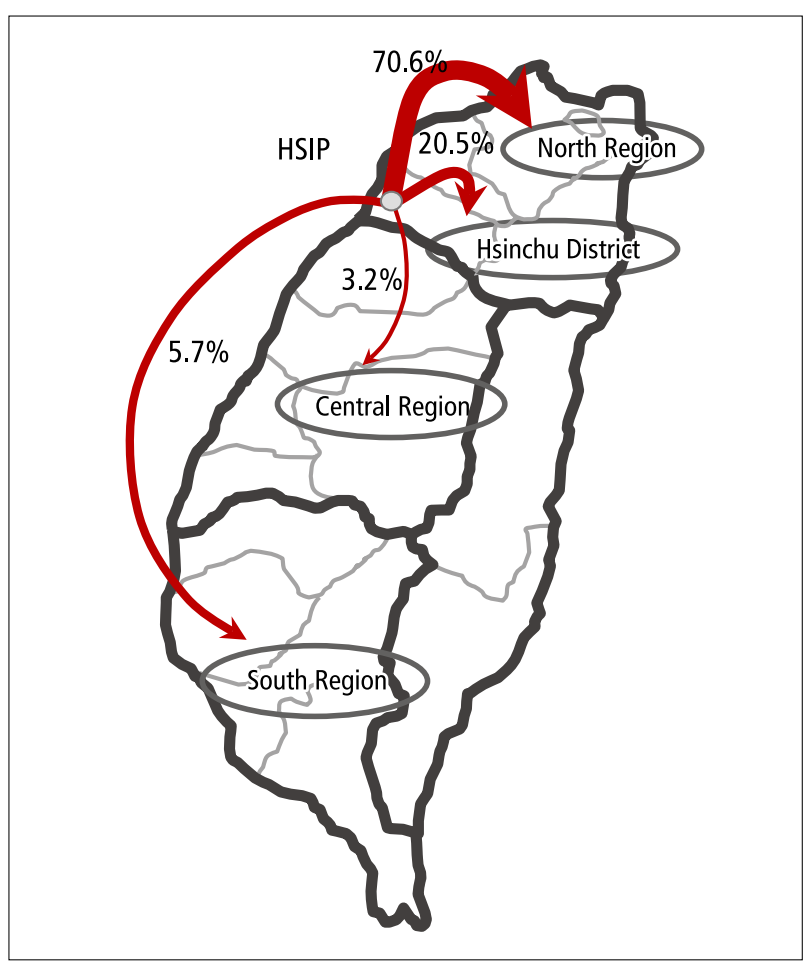

Fig. 3. Output Network in Hsinchu Technopolis

This trend has accelerated since 2000. Consequently, innovation and production links that have developed in the Hsinchu industrial cluster hide specific interactive factors that have attracted firms to the area to compete for economic agents with endowments of new knowledge, high-tech personnel, knowledge, information and other interaction advantages, while simultaneously becoming magnets attracting high-tech talent to the area. Consequently, this investigation analyzes how the high-tech talent interactions influence innovative activities.

\footnotetext{
${ }^{3}$ Technological cooperation contracts and trade networks that originate at the HSIP show that the degree of industrial clustering in the Hsinchu area is highest in the integrated circuit and opto-electronics industries, while the computer and peripherals, and telecommunications industries, tend to cluster throughout the entire northern region. Kung (1999) addressed the agglomeration of spin-offs in these four industries by analyzing the family trees of enterprises in the area.
} 


\section{Special Contribution}

\subsection{Information Mobility in Technological Communities}

The close proximity to research/academic institutions and large firms promotes knowledge spillover. Moreover, the mobility of knowledge and information among high-tech personnel within the workplace reinforces the spill-over effect. A study of the processes by which knowledge and information are obtained by workers while at work revealed that, first, when high-tech personnel encountered difficulties or problems at work, almost $72 \%$ of them followed internal company procedures and obtained the information they required via formal information channels, while the remaining 28\% obtained this information via informal channels, for example through seeking the assistance of, or discussion with, friends in related industries within or outside the HSIP.

Second, those who used informal channels to gain knowledge or information tended to switch jobs within the HSIP more frequently than those who obtained information via formal channels. Personnel who obtained knowledge or information via formal channels tended to prefer to work at large and prestigious companies within the HSIP. However, most personnel who obtained knowledge or information through informal channels tended to favor small, high-profit firms within the HSIP, with their second choice being new firms, with significant potential for innovative activities.

To seek knowledge or information via informal channels, $50 \%$ of respondents confirmed the accuracy or validity of the information obtained through numerous cross-references. Another 32\% of users of informal channels determined the accuracy according to the understanding of the information suppliers. Firms within related industries are really competing with one another; therefore, information from a single source is unreliable. This situation is frequently referred to by papers on industrialtheory discussing competition and cooperation among employers and employees, respectively. The extent of competition and cooperation varies significantly, mainly because most information is obtained via informal channels, and not only varies according to the supplier, but also requires verification from other sources. One possible positive result of the abundant and diverse range of sources of information made available by this type of cooperation is that high-tech personnel benefit from more ideas and stimuli.

Consequently, the high-tech human resource market, which has been developed by the agglomeration of firms in related industries in the Hsinchu area, is not the only important influence on production, and competition among hightech personnel to realize increased knowledge value is another determining factor. Moreover, firms can establish new knowledge teams or opportunities from this pool of competing experts. Firms may even be able to establish a network to facilitate the movement of information across various fields and regions.

\subsection{Human Resource Mobility in Technological Communities}

Through survey, it shows that the rate of turnover of engineers and skilled employees exceeded that of all other hightech personnel in firm manufacturing departments. Meanwhile, the second highest rate of turnover was for skilled personnel in sales and R\&D departments. Of these, approximately $37 \%$ changed jobs every two to three years and $25 \%$ changed jobs every one to two years. In contrast, $42 \%$ of high-tech personnel expected to remain in their current place of employment for up to three years; $28 \%$ estimated that they would keep the same job for three to six years, and just $6 \%$ planned to remain in the same job for over ten years.

However, a comparison of the expected period in a particular job with the actual period in a particular job demonstrated that the actual time spent with one employer before switching to another job was considerably less than that respondents specified as the time they expected to spend in a job. This finding suggests that specific factors influence mobility. These factors can be divided into four major categories - first, unattractive salary and bonuses (profit-sharing) at the current place of employment (accounting for 56\% of mobility); second, lack of challenging work at the current place of employment (15\%); third, transition of an entire work team to a new place of work owing to an innovative technology (9\%), and, fourth, desire of an individual to remain within the HSIP despite their job being moved elsewhere (8\%). Moreover, statistical analysis demonstrated that the frequency with which personnel who listed 'unattractive salary and bonuses at the current place of employment' and 'transition of the entire work team to a new place of work as a result of innovative technology,' as influences on mobility, was generally once every two to three years.

The results also demonstrated that most of those surveyed, namely around $60 \%$, claimed that the most popular destinations within the HSIP were large, prestigious firms, 
regardless of their innovative ability. ${ }^{4}$ Newly created firms ${ }^{5}$ explained just $17 \%$ of movement between jobs. Since employees work for these newly created firms, they would generally take higher risk and lower salary than the large and prestigious firms. This finding indicates that the career paths followed by most R\&D and skilled technical personnel are driven primarily by the desire to secure employment at large-scale, mature firms with a good reputation, and that such personnel are most attracted by company profit-sharing schemes and good company outlook. This result in turn indicates that such personnel lack the risk-tolerant mind-set required for participating in the initial stages of new knowledge-based firms, as well as the entrepreneurial spirit required to establish their own companies.

Since most job turnover of skilled personnel employed within the HSIP occurs within three years of taking a job, the nature of subject relationships with former colleagues after changing jobs is interesting. This question is especially interesting when the new employer is competing with the previous one. It was found that most personnel who changed jobs every three years either developed competitive rela- tions with their ex-colleagues or minimized contact. Interaction is mainly through informal personal contact or social gatherings. This type of contact is not only helpful in effectively timing job changes, but also in enabling teams working with innovative technologies to make career transitions when their technology matures, or establish new spinoffs.

\subsection{Innovative Chains within Technological Communities}

The analytical results of this investigation indicate that inhouse R\&D, local academic and research institutes, and foreign companies are the three main sources of technology for firms in the HSIP. R\&D cooperation or product design cooperation among firms represents less than $30 \%$ of all responses. R\&D cooperation is mostly on different hierarchy in related industries. In expanding their own personal professional networks $<$ Table $5>$ and $<$ Table $6>$, individuals who interacted face-to-face on at least a weekly basis developed their networks mostly through informal personal contact or social gatherings (about 30\%). Similarly, most skilled personnel

Table 5. Frequency of Face-to-Face Interaction vs. Expanding Individual Professional Network

\begin{tabular}{lcccc}
\hline & & \multicolumn{2}{c}{ Frequency of face-to-face } \\
\cline { 2 - 5 } & At least 3 times weekly & $1-2$ times weekly & $1-3$ times monthly & Less than 1 time monthly \\
\hline Attend project & $4.0(0.0)$ & $1.8(00.0)$ & $4.5(0.0)$ & $0.0(0.6)$ \\
Education and training & $3.5(0.0)$ & $5.0(00.0)$ & $7.5(3.6)$ & $3.4(8.7)$ \\
Attend seminar & $4.5(0.0)$ & $5.2(00.0)$ & $8.0(4.6)$ & $15.0(3.5)$ \\
Informal interaction or meeting & $14.0(2.9)$ & $16.0(10.2)$ & $6.5(29.8)$ & $1.1(36.1)$ \\
\hline
\end{tabular}

Notes: ( ) Denotes the Frequency of Face-to-Face without R\&D/Design Cooperation.

Table 6. Personnel with or without R\&D/Design Cooperation vs. Expanding Individual Professional Network

(\%)

\begin{tabular}{lcccc}
\hline & Attend project & Education and training & Attend seminar Informal interaction or meeting \\
\hline With R\&D/design cooperation & 3.1 & 5.8 & 9.8 & 11.3 \\
Without R\&D/design cooperation & 0.4 & 8.6 & 5.7 & 55.7 \\
\hline
\end{tabular}

\footnotetext{
${ }^{4}$ It implies that a few larger and/or prestigious firms currently maintain good returns, but do not actively promote R\&D investment. Such firms are likely to gradually move to China in 5-8 years after set up (Hu et al. 2003, p.78).

5 Generally, newly created firms have large capacity for innovation, and most of them are spin-offs, for example from ITRI, Chiao-Tung University, and Silicon Valley.
} 


\section{Special Contribution}

who were not involved in R\&D or design cooperation activities tended to expand their personal professional networks informally via personal contacts or social gatherings; however, the frequency of their interactions was significantly lower than that of personnel involved in cooperation activities.

Most firms in related industries are competing with each other. The primary reasons for these firms concentrating in the Hsinchu area are the advantages of ease of obtaining information, availability of industrial support, presence of economic agents, and other reasons related to better understanding of their competitors. Firm cooperation usually takes the form of international alliances with foreign companies, but cooperation with other firms around the HSIP also occurs in the form of horizontal collaboration across related industries or vertical integration, such that relations between firms are simultaneously competitive and cooperative, creating a firm competitive advantage for the HSIP and surrounding area (Hu et al. 2002). Thus, interactive networks among local firms make significant contribution to the development of specific innovative activities.

\section{DEVELOPMENT AND GEOGRAPHIC TRANSFORMATION OF PRODUCER SER- VICES IN THE HSINCHU TECHNOPOLIS}

After the previous overview of socioeconomic transformation and innovative activity in Hsinchu technopolis, this paper reviews the development of producer services that have become an integral part of the industrial development model of Hsinchu technopolis. The definition of producer services, the authors adopted a broader definition, i.e., any service functions that can be operated for the consumption of companies and organizations, including 1) transportation, logistics, communication, 2) finance, insurance, real estate, and 3) business services.

The emergence and expansion of innovation increasingly depends on new technology and knowledge. New technology and knowledge are not just created in companies' internal R\&D labs but can also be derived through intensive interactions, communication and exchange of information among companies and academic research institutions. Producer services appropriately play a key role in this interface. They serve as a bridge and exchange center between technical and business experts and localized knowledge and capabilities. This role led to producer services being seen as shared inno- vators of small to medium size companies. Producer services provide services that result in an intensive interactive process, in which producer services continue to evolve in order to meet the demand of their clients (Hu et al. 2006).

The cross-border division of labor in high-tech industries resulting from globalization inevitably reconstructs production methods, organization and geographic structure. In the two decades of development of HSIP, HSIP's vicinity gradually formed a distinctive and strong network including production, incubation and R\&D activities (Hu et al. 2002). Within this network, producer services not only provide a crucial interface between the supportive environment and technological infrastructure but also effectively fill the role in linking Hsinchu to the global network.

Before the establishment of HSIP, the Hsinchu area's industrial structure was dominated by secondary level industries. The establishment of HSIP in 1980 led to the innovation and advancement of manufacturing industries in Taiwan, which further attracted more firms moving to HSIP. The activities in HSIP also stimulated the industrial and economic development of its vicinity and formulated a new industrial network in Hsinchu technopolis. In order to meet the service demand of global technology and to serve firms in and around HSIP, the level of service industries was also gradually elevated and certain related service industries, such as banking, insurance, storage, logistics and transportation, and information technology, began to cluster around HSIP. These specialized service businesses provide numerous resources and services to satisfy their customers in HSIP and the Hsinchu area.

Interactions in Hsinchu Technopolis include primarily production, R\&D, innovation, information exchange and other related activities. The host city of HSIP, Hsinchu City, responding to the impact of clustering of industries, began to integrate various resources and professional service industries to enhance the development of the local industrial network. Among producer services, finance, insurance and real estate industries enjoyed the most significant development $<$ Fig. $4>$. Before 1991, there were only a small number of new companies (about three to twenty five) that joined these industries annually. After 1991, there was an increase of 80 to 100 annually. This dramatic growth may also be the result of deregulation of the banking industry that led to the emergence of numerous new banks. However, the demand originating from a geographic industrial cluster remains an important factor contributing to this growth. 


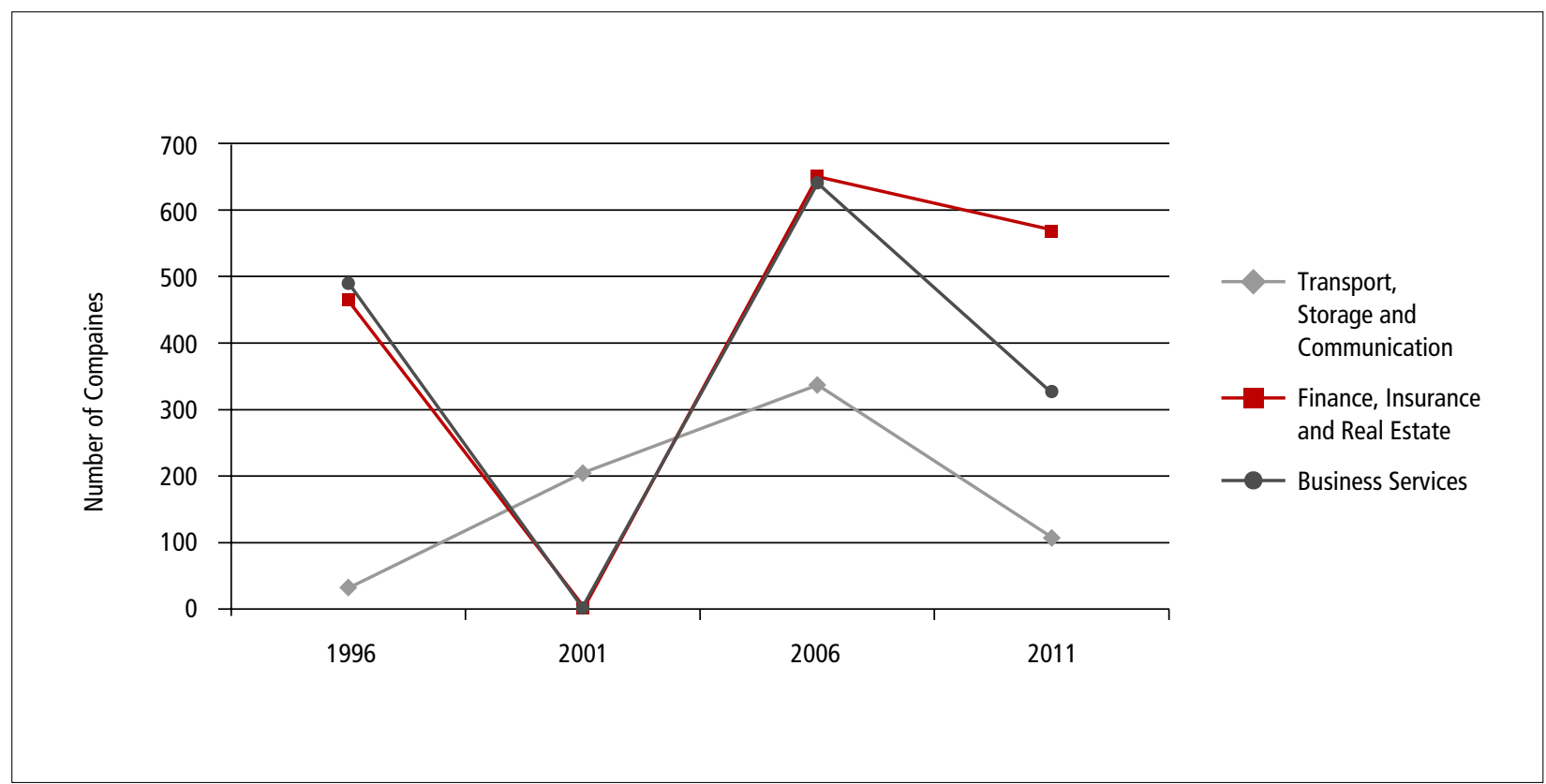

Fig. 4. Increase of the Number of Companies in Producer Services in the Hsinchu Area

Source: The Report of 2011 Industry, Commerce and Service Census

Since 1986, there has been a significant increase in the number of business services in Hsinchu City. The fastest growing periods were first between 1989 and 1991, and later after 1995. Among business services, the information and software service industry grew the most, followed by advertising, marketing, consulting, and product design. The growth in Hsinchu County, however, was not significant until after 1992, when the growth rate reached 40 new companies per year. Cheaper land in Hsinchu County provides space for leasing industries, therefore, the growth of construction machinery leasing industry was the most significant in Hsinchu County, followed by consulting, marketing and information services. In summary, business services chose different geographic locations because of different characteristics of Hsinchu City and Hsinchu County.

There were two peaks in the development of producer services in the Hsinchu area. The first peak was the development of host city Hsinchu when the interactive effects of HSIP industries and producer services began to emerge. The second peak was the development of accessible areas through the expansions and connections of local industrial production networks, which attracted more producer services and increased interactive activities. As evident in the Hsinchu area, producer services in Hsinchu City expanded to accessible areas around HSIP via major transportation links. In fact, these interactions accumulated and led to the increasing demand for and dependency on producer services, particularly KIBS industries. With such demand for a variety of professional services, a network of business services began to emerge, as concluded by Feldman and Florida (1994).

\section{CONCLUSIONS}

After the establishment of ITRI in 1973, the HSIP was established in 1980 aiming to promote the national economic growth and balanced regional development with mass production capabilities for IT industries. Experience of 30 years is long enough for a comprehensive evaluation of the long term impacts of a science park. It is evident that HSIP has significantly attracted inwards migration of technical labor forces and also promoted urban development around the HSIP as technopolis. In fact, it also proves that HSIP has evolved as a technological infrastructure for high-tech research and development activities with global competitiveness. The accumulated spin-off effects of innovative production networks were also reflected in the evolution of the local socioeconomic environment. 


\section{Special Contribution}

Although communication costs have decreased considerably because of globalization and the improvement of communication technology, face-to-face interactions remain essential for the spatial agglomeration of high-tech innovation owing to the ambiguity and uncertainty of new innovative knowledge. The experience of Hsinchu technopolis has well demonstrated the significant importance of social interaction to the development of IT industry when they are facing to critical global completion.

Most previous studies have generally concluded that significant positive correlations exist between firm innovative activities and factors such as spatial proximity with academic and research institutions, and the level of industrial clustering. That is, firms in the industrial cluster can take advantage of the healthy and productive industrial environment with abundance of specialized human resources. The survey of high-tech professionals in HSIP summarized in this paper confirms such theory by showing that the close spatial clustering of technology firms in Hsinchu technopolis has favored repeated knowledge agent spin-offs and high-tech personnel mobility that which then clearly influences innovative activity of technology-based firms. The local innovation and production network formed by the HSIP, the surrounding area and technological infrastructure, and an environment of innovation with significant related knowledge and informal interactions created by nearby universities and research institutions (ITRI, Chiao-Tung University and ChingHua University), not only strengthened the local agglomeration economy, but also became a major force for enhancing the competitive advantage of local industry.

Considering factors such as the intentions of R\&D investment and activity, technology transfers, human resource spin-offs, production and trading interactions, and so on, it can be concluded that the northern region of Taiwan comprises a complete industrial cluster. During the early stages of new production and the spinning-off of a new firm, firms in the northern Taiwan area tend to locate around ITRI and the HSIP. When these firms have developed mature and extensive relationship networks, as demonstrated by an analysis of their production and trade interactions, they tend either to put down roots and remain in an appropriate location within the northern Taiwan industrial cluster or alternatively establish connections with other clusters in order to integrate cross-boundary resources. Additionally, the synergies achieved through the linking with ITRI (the first R\&D park) and HSIP (the first Production and R\&D park) in
Taiwan also promoted the formation of an innovation cluster in Hsinchu technopolis, and expanded the production cluster over the northern region of Taiwan. Furthermore, the innovation cluster was then reinforced by the technological infrastructure.

As it was argued by Lin (1997) that the HSIP is a successful project in terms of economic growth and technology development, yet, the spatial pattern differed from what it was planned. More specifically speaking, infrastructure development and land development control in HSIP's surrounding areas were beyond the scope of the original plan. Along with the gradual expansion of HSIP boundary, the freeway system connecting to the park has been extended and expanded accordingly. Among all major infrastructure development projects, the completion and operation of both National Freeway No.3 in 2004 and High Speed Rail (HSR) in 2007 have significantly influenced the spatial pattern of Hsinchu technopolis development. Because of the high speed transportation network, the integration of Hsinchu technopolis and Taipei metropolitan will be more intensified.

Looking into the future, technology progress, especially in the area of IT industry, will still be the key factor for city competitiveness of Hsinchu. In addition, the relationship between Taiwan and China will influence the development of Hsinchu technopolis eventually. As it is shown that following the emergence of the new linkage of the United States, Taiwan and China during the mid-1990's, the establishment of cross-border interactions among clusters has attracted considerable interest of high-tech firms and researchers. Cross-border interactions among clusters have significantly changed the conventional perspective of cluster dimensions and geographical connections.

Despite the China factor, social interaction network among high-tech firms, labors, research institutions and universities will still be an valuable invisible asset for Hsinchu technopolis simply because it can be easily copied and exported. As it is demonstrated in this paper that firms still rely on spatial proximity, establishing their R\&D centers in the Hsinchu or northern Taiwan, to fulfill the practical requirements for face-to-face interaction and reduce the risks associated with uncertainty and technological infrastructure costs. After all, industrial clusters with close spatial relations and deep interactions within the technological community have better opportunity to enjoy advantages in knowledge competitiveness. 


\section{REFERENCES}

Audretsch, D.B. (1998) "Agglomeration and the location of innovative activity," Oxford Review of Economic Policy 14(2): 18-29.

Baptista, R. (1996) "Research round up: industrial clusters and technological innovation," Business Strategy Review 7(2): 59-64.

Bass, S.J. (1998) "Japanese research parks: national policy and local development," Regional Studies 32(5): 391-403.

Chang, S.-L., Lee, Y.-H., Lin, C.-Y., and Hu, T.-S. (2010) "Consideration of proximity in selection of residential location by science and technology workers; case study of Hsinchu, Taiwan," European Planning Studies 18(8): 1317-42.

Feldman, M.P., and Florida, R. (1994) "The geographic sources of innovation: technological infrastructure and product innovation in the United States," Annals of the Association of American Geographers 84: 210-29.

Hu, T.-S., Chang S.-L., Lin C.-Y., and Chien, H.-T. (2006) "Evolution of Knowledge Intensive Services in a High-Tech Region - the Case of Hsinchu, Taiwan," European Planning Studies 14(10): 1363-85.

Hu, T.-S., Lin, C.-Y., and Chang, S.-L. (2005a) "TechnologyBased Regional Development Strategies and the Emergence of Technological Community: A Case Study of HSIP, Taiwan," Technovation 25(4): 367-80.

Hu, T.-S., Lin, C.-Y., and Chang, S.-L. (2005b) "Role of Interaction between Technological Communities and Industrial Clustering in Innovative Activity: The Case of Hsinchu District, Taiwan," Urban Studies 42(7): 113960.

Hu, T.-S., Heish, H.-N., and Lin, C.-Y. (2003) "Rethink the major elements and development of regional innovation environment of technology-based industries," Urban Planning Forum 145: 74-80. (In Simple Chinese).

Hu, T.-S., Heish, H.-N., and Wang, J.-Y. (2002) "Socioeconomic Analysis of the Hsinchu Technopolis Evolution in Taiwan: 1980 - 2000," City and Planning 29(1): 3765. (In Chinese).

Kung, H.-F. (1999) A Study of Spin-Off Phenomenon of High-Tech Industries Using Hsinchu District as a Case Study, Research Project of the National Science Council, Taiwan. (In Chinese).

Lin, C.-Y. (1997) "Technopolis development: An assessment of the Hsinchu experience," International Planning
Studies 2(2): 257-72.

Masser, I. (1991) "By accident or design: Some lessons from technology led local economic development initiatives," Review of Urban and Regional Development Studies 3(1): 78-93.

Oh, D.-S., and Cha, S.-R. (2001) "Critical success factors of technopolis for regional innovation: Case study of Daedeok Science Town," Paper presented at the International Symposium on City Planning 2001, Taejon, Korea, 17-18 August 2001.

Oh, D.-S. (1995) "High technology and regional development policy: an evaluation of Korea's technopolis program," Habitat International 19: 253-68.

Saxenian, A. (1994). Regional Advantage: Culture and Competition in Silicon Valley and Route 128. (Boston: Harvard University Press).

Westhead, P., and Batstone, S. (1998) "Independent Technology-based Firms: the perceived benefits of a science park location," Urban Studies 35(12): 2197-219. 